\title{
Redactioneel
}

\section{Het etmaal van de com- municatiewetenschap 2009: Een gelegenheid tot ontmoeting}

\author{
Martine van Selm, Ivar Klinkenberg, Margot van der \\ Goot Q Oscar Peters
}

Dit themanummer van het Tijdschrift voor Communicatiewetenschap is voortgekomen uit het negende Etmaal van de Communicatiewetenschap, dat in februari 2009 plaatsvond aan de Radboud Universiteit in Nijmegen. Het Etmaal van de Communicatiewetenschap is een initiatief van de Netherlands School of Communication Research (NESCOR), de school waarbinnen onderzoek op het gebied van de communicatiewetenschap in Nederland verenigd wordt. De betrokkenheid van communicatiewetenschappers uit Vlaanderen hierbij wordt overigens steeds groter, waardoor het Etmaal in toenemende mate een Nederlands/Vlaamse coproductie is geworden. Zo vond het Etmaal van 2007 plaats in Antwerpen, hadden we dit jaar contactpersonen bij vier Vlaamse universiteiten, kwam keynote spreker prof. dr. Jan Van den Bulck uit Leuven en zullen de eerstvolgende edities van het Etmaal in Gent respectievelijk Leuven gehouden worden. Het Etmaal kan mede hierdoor ook in de komende jaren zijn functie als trefpunt voor communicatieonderzoekers in de lage landen blijven vervullen. Ook onderzoek dat niet bij NESCOR is ondergebracht, maar wordt gedaan aan instellingen daarbuiten weet inmiddels zijn weg naar het Etmaal van de Communicatiewetenschap goed te vinden.
Het congres mocht zich dit jaar weer verheugen in een groot aantal inzendingen. Dit resulteerde in een mooi programma bestaande uit I30 paperpresentaties, 25 posterpresentaties en 2 panels. Er waren meer dan 200 deelnemers en er was persaandacht voor het in Nijmegen gepresenteerde onderzoek. De Best Paper Award, die jaarlijks wordt uitgereikt aan het beste paper geschreven door een promovendus/da, was voor Rosa van Santens Popularization and personalization in political television journalism: A conceptual exploration (Universiteit van Amsterdam), dat inmiddels gepubliceerd is in nummer 2 van de huidige jaargang (2009) van dit tijdschrift. De jury voor deze prijs bestond uit een groep collega's afkomstig van diverse Nederlandse en Vlaamse universiteiten en werd voorgezeten door prof. dr. Fred Wester (Radboud Universiteit Nijmegen). De NESCOR Dissertation Award werd uitgereikt aan Rens Vliegenthart (Universiteit van Amsterdam). Zijn proefschrift Framing Immigration and Integration: Facts, Parliament, Media and Anti-Immigration Party Support in the Netherlands (verdedigd aan de Vrije Universiteit) werd verkozen tot de beste communicatiewetenschappelijke dissertatie gepubliceerd in 2007. De jury voor deze prijs bestond uit vier promovendi werkzaam aan de Universiteit Twente, de Radboud Universiteit Nijmegen, de Vrije Universiteit en de Universiteit van Amsterdam. Esther Rozendaal (Universiteit van Amsterdam) lichtte het juryrapport toe en reikte de prijs uit. De vier bijdragen in dit themanummer laten net als het Etmaal van de Communicatiewetenschap een ontmoeting zien: tussen fundamenteel en min of meer toegepast onderzoek, tussen verschillende onderzoeksmethoden en tussen theoretische perspectieven. Bij de keuze van de papers voor dit themanummer heeft de gastredactie om te beginnen op basis van het congresprogramma per sessie enkele papers geselecteerd. De auteurs 
van deze papers werden benaderd met het verzoek hun paper te bewerken tot een artikel. De auteurs die hiertoe bereid waren, ontvingen twee blind reviews van hun artikel. Op basis van deze beoordelingen bleven vier artikelen over die, al dan niet na nog een ronde van revise en resubmit, gepubliceerd konden worden.

Globaal gezegd behandelen de artikelen de volgende thema's vanuit een communicatie-invalshoek: onderwijs (Walma van der Molen \& Peijs), merkreclame (Van Reijmersdal, Smit \& Neijens), duurzaamheid (Van Gorp \& Van der Goot) en vriendschap (Vanden Abeele \& Roe).

De bijdragen tezamen vormen een palet aan methoden waarmee zowel hypothesetoetsend als exploratief-beschrijvend onderzoek uitgevoerd is. Deze onderzoeksmethoden variëren van een kwalitatieve inhoudsanalyse (Van Gorp $\&$ Van der Goot), een webenquête (Vanden Abeele \& Roe) tot experimenteel onderzoek in enerzijds een basisschoolsetting onder leerlingen uit groep 7 (Walma van der Molen \& Peijs) en anderzijds een natuurlijke thuissituatie onder Nederlandse televisiekijkers, met behulp van een Intomart GfT Online Panel (Van Reijmersdal, Smit \& Neijens).

Ook de theoretische invalshoeken van de studies uit dit themanummer lopen sterk uiteen. Ze varieren van de theorie van het ervaringsleren (experiential learning) (Walma van der Molen \& Peijs), de uses and gratifications-benadering en de spill over-theorie (Van Reijmersdal, Smit \& Neijens), framing-theorie en meer specifiek framingtheorie vanuit de constructionistische benadering (Van Gorp \& Van der Goot), tot het begrippenpaar 'bonding and bridging' uit Putnams theorie over sociaal kapitaal (Vanden Abeele \& Roe). De studies dragen elk op eigen wijze bij aan inzicht in de aard of toepassingsmogelijkheden van de gehanteerde theoretische noties.

Walma van der Molen (Universiteit Twente en Universiteit van Amsterdam) en Peijs nemen in 'Tell me and I'll forget - Show me and I may remember - Involve me and I'll understand: leereffecten van educatieve software vergeleken met een traditionele lesmethode' de leereffectiviteit van educatieve games onder de loep. In dit onderzoek vergelijken zij deze met traditioneel leermateriaal. Zij tonen aan dat informatie die op zinnige wijze in een spel geïntegreerd is op de korte termijn beter herinnerd wordt. Naar aanleiding van dit onderzoek wijzen de auteurs op het belang van nadere studie naar de herinnering van informatie op de langere termijn en naar het tussenliggende proces van informatieverwerking.

Van Reijmersdal, Smit en Neijens (Universiteit van Amsterdam) onderzoeken in 'Brand placement: het effect van programmacontext op merkherkenning, merkattitude en gedrag' hoe programmagenre, waardering voor het programma en de informationele waarde ervan een rol spelen bij brand placement in televisieprogramma's. Brand placement is de integratie van merken in redactionele media-inhoud met een commercieel doel. De studie laat zien dat de informationele waarde van televisieprogramma's bevorderend werkt voor merkherkenning, merkattitude en merkgedrag en dat ook programmagenre een rol speelt. Merkherkenning en voorgenomen gedrag werden meer bevorderd door placement in special interest-programma's (hier Top Kok en Eigen Huis en Tuin) dan in general interest-programma's (hier Evelien en GTST). Als implicatie voor de reclamepraktijk benadrukken de auteurs het belang van het juiste type programma voor het inzetten van brandplacement.

Van Gorp (Katholieke Universiteit Leuven) en Van der Goot (Radboud Universiteit Nijmegen) onderzoeken in 'Van Frankenstein tot de Goede Moeder: de inzet van frames in de strategische communicatie over duurzaamheid' de manier waarop belanghebbende partijen op het gebied van duurzaamheid hun boodschappen over dit thema inkaderen en presenteren. Van Gorp en Van der Goot ontdekten zes frames in krantenartikelen, brochures, advertenties en productetiketten over duurzaamheid. Iedere cultuur beschikt over een repertoire aan frames die de leden kunnen gebruiken om betekenis te verlenen aan allerlei fenomenen waarmee ze worden geconfronteerd. Zo kan het Frankensteinframe gebruikt worden om de urgentie van duurzame ontwikkeling aan te geven. De auteurs concluderen dat er geen één-op-éénrelatie is tussen specifieke frames en een bepaalde stakeholder. Wel lijken sommige frames minder goed met elkaar verenigbaar. Een voorbeeld hiervan is het moeilijk samengaan van het 'al-het-goede-van-denatuurframe' met het 'vooruitgangsframe'. In toekomstig onderzoek zouden Van Gorp en Van der Goot graag diachronisch kijken naar de 
opkomst en veranderingen van bepaalde frames en naar de spreiding van frames binnen diverse typen mediaboodschappen.

Vanden Abeele en Roe (Katholieke Universiteit Leuven) leggen in 'Nieuw leven, oude vrienden? Een longitudinale studie naar het effect van communicatietechnologie op het sociaal kapitaal van eerstejaarsstudenten in het hoger onderwijs' een verband tussen de intensiteit van sms-, instant messaging (vanaf nu im) en e-mailgebruik van eerstejaars studenten en de verbondenheid met vroegere vrienden en nieuwe vrienden. Via een webenquête onder Vlaamse studenten, uitgezet in drie golven met zes maanden tussentijd, komen de auteurs tot de conclusie dat de studenten gedurende hun eerste jaar een afname ervoeren in de verbondenheid met vroegere vrienden en een toename in de verbondenheid met nieuwe vrienden. $\mathrm{Zij}$ vinden echter ook dat hoe meer men met die nieuwe vrienden sms't, im't of mailt, hoe minder snel de verbondenheid met hen toeneemt. Om deze laatste opvallende bevinding te kunnen plaatsen, is volgens de auteurs meer onderzoek nodig onder studenten uit het hoger onderwijs waarin ook aandacht is voor het (frequente) gebruik van sociaalnetwerksites zoals Facebook, of van microblogging zoals Twitter.

Voor de totstandkoming van dit themanummer willen wij de auteurs bedanken voor hun inzet, de hoofdredacteur van het Tijdschrift voor Communicatiewetenschap, Connie de Boer, voor haar adviezen en hoofdredactiewerk en tot slot de reviewers, die vaak op korte termijn hun kundig oordeel over de papers naar ons toestuurden. Wij zien uit naar het Etmaal van de Communicatiewetenschap in februari 2010 in Gent en het daar inmiddels bijbehorende themanummer van het Tijdschrift voor Communicatiewetenschap.

Martine van Selm (M.vanSelm@maw.ru.nl), Ivar Klinkenberg (I.Klinkenberg@maw.ru.nl) en Margot van der Goot (M.verderGoot@maw.ru.nl) werken aan de Radboud Universiteit Nijmegen. Oscar Peters (O.Peters@gw.utwente.nl) werkt aan de Universiteit Twente 